\title{
Vital Signs Data Collection Day
}

National Cancer Institute

\section{Source}

National Cancer Institute. Vital Signs Data Collection Day. NCI Thesaurus. Code C83455.

The day of the week vital signs data was collected. 